NOTE

\title{
Mixed testicular neoplasia in a short beaked common dolphin Delphinus delphis
}

\author{
J. Díaz-Delgado ${ }^{1}$, A. Espinosa de los Monteros ${ }^{1}$, C. Fernández-Maldonado ${ }^{2}$, \\ M. Arbelo ${ }^{1}$, O. Quesada-Canales ${ }^{1}$, M. Andrada ${ }^{1}$, A. Fernández ${ }^{1, *}$ \\ ${ }^{1}$ Veterinary Histology and Pathology, Institute of Animal Health, Veterinary School, \\ University of Las Palmas de Gran Canaria, Trasmontaña s/n, Arucas 35413, Las Palmas de Gran Canaria, Spain \\ ${ }^{2}$ Agencia Medio Ambiente y Agua de Andalucía, Consejería de Medio Ambiente, Junta de Andalucía, Johan Gutenberg 1, \\ Sevilla 41092, Spain
}

\begin{abstract}
A diagnosis of mixed testicular neoplasia in a short beaked common dolphin Delphinus delphis involving a Sertoli cell tumor, an interstitial (Leydig) cell tumor and a seminoma is presented. Lymphatic spread of the Sertoli cell tumor to an adjacent retroperitoneal lymph node was observed. Testicular neoplasms have been infrequently reported in marine mammals. Demonstration of clinical signs and further health implications is extremely challenging when dealing with non accessible wildlife species, such as dolphins. However, metastatic potential for these neoplastic conditions should be considered.
\end{abstract}

KEY WORDS: Testicular neoplasms $\cdot$ Cetacean $\cdot$ Collision tumor $\cdot$ Delphinus delphis $\cdot$ Germ cell-sex cord stromal tumor · Interstitial (Leydig) cell tumor $\cdot$ Seminoma $\cdot$ Sertoli cell tumor

Testicular neoplasms have been rarely described in the cetacean scientific literature. An unspecified testicular tumor was noted by Mawdesley-Thomas (1975) in a bottlenose dolphin Tursiops truncatus. Cowan et al. (1986) and Geraci et al. (1987) described 2 cases of interstitial (Leydig) cell tumor in common dolphins Delphinus delphis. Estep et al. (2005) reported a seminoma with metastasis to a retroperitoneal lymph node and a Sertoli cell tumor in a spotted dolphin Stenella frontalis, in which a pheochromocytoma was concomitantly observed, and a seminoma with metastasis to the mesentery in a bottlenose dolphin.

This report describes a mixed testicular neoplasia (collision tumor) involving a Sertoli cell tumor, an interstitial (Leydig) cell tumor and a seminoma in a short-beaked common dolphin.

An adult male short-beaked common dolphin in good nutritional condition was found stranded on the coast of Almeria (Western Mediterranean Sea). The decomposition status was fresh, and the animal's total length was $203 \mathrm{~cm}$.

At necropsy, 2 masses were observed in the abdominal cavity. One of them, which measured $4 \times$ $2.7 \times 2.3 \mathrm{~cm}$, was associated with the left testicle and showed poor demarcation from the adjacent testicular parenchyma (Fig. 1). The other, $8 \times 6 \mathrm{~cm}$ in size, was closely related to the right testicle and consistent with a retroperitoneal lymph node, firmly attached to the peritoneum. Samples from different organs, including testicle-related lesions, were preserved in buffered formalin $(10 \%)$, embedded in paraffin, sectioned at $5 \mu \mathrm{m}$, and stained with hematoxylin and eosin.

Histologically, in both testicles, 3 microscopically distinguishable neoplastic cell populations were observed (Fig. 2). These cells formed multifocal solid nodular masses. Neoplastic masses were non-encap- 
sulated, demonstrated expansile growth, and varied in size from 1.3 to $0.2 \mathrm{~cm}$. Atrophy of adjacent seminiferous tubules and parenchymal fibrosis were prominent.

In the first cell population, solid nodules were mainly composed of pleomorphic cells, comprising multifocal pallisading cuboidal to spindle-shaped cells, supported by a thin connective stroma; the remaining cells were polyhedral and arranged in sheets. Cells demonstrated poorly distinct borders, with a moderate amount of finely granular eosinophilic cytoplasm. Rare, small intracytoplasmic vacuoles were seen. Nuclei were round to elongate and finely stippled with heterochromatic chromatin. Anisocytosis and anisokaryosis were noted. Mitoses were rare. Macrophages and multinucleated giant cells engulfing yellow material were multifocally present in areas intimately related to this first group of neoplastic cells. Scant polymorphonuclear intratubular infiltration was seen associated to these areas. Based on histopathologic findings, a diagnosis of Sertoli cell tumor was made (Fig. 3). Intravascular clusters of Sertoli cells forming emboli were seen in vessels adjacent to solid nodules. The right adjacent retroperitoneal lymph node demonstrated clusters of these neoplastic Sertoli cells in capsular lymphatic vessels and subcapsular sinuses, but no lymph node masses were evident (Fig. 4).

The second set of proliferative masses was well demarcated and more densely cellular than the first. They showed polyhedral cells arranged in an irregular acinar pattern commonly lining blood vessels, supported by a fibrovascular stroma. However, disorganized cells exhibiting a growth in sheets, tightly packed, were also evident. Cell borders were poorly demarcated, and cytoplasm was intensely eosinophilic, with central, heterochromatic nuclei with finely stippled chromatin. Mitotic figures were rare. Hemorrhages and necrosis usually coexisted associated with this pattern of neoplastic cells. A diagnosis of an interstitial (Leydig) cell tumor was made (Fig. 5).

The third cell population constituted densely cellular areas, poorly demarcated from those described as neoplastic interstitial cells, exhibiting a diffuse growth in sheets. Cells were large, round to polyhedral, with moderately distinct borders and a pale eosinophilic cytoplasm. Large vesicular nuclei with evident nucleoli were observed. Mitotic figures were numerous and variable, averaging 3 per $40 \times$ high power field (HPF). A diagnosis consistent with a seminoma was determined (Fig. 6).

In veterinary pathology, Sertoli cell tumors, seminomas and interstitial (Leydig) cell tumors have been broadly described in dogs, and to a lesser extent in stallions, rams, cats, bulls, and goats (Maclachlan \& Kennedy 2002). A few reports of testicular neoplasia in other species as ferrets and rabbits exist (IrizarryRovira et al. 2008, Batista-Arteaga et al. 2011). In laboratory animals, an interstitial (Leydig) cell tumor in mice and a mixed Sertoli-Leydig cell tumor in rats have been described (Rehm \& Waalkes 1988, Mitsumori et al. 1989).

In wildlife, an interstitial (Leydig) cell tumor in an eland Taurotragus oryx, a Sertoli cell tumor in a captive jungle cat Felis chaus, a seminoma in a sea otter Enhydra lutris, and a testicular teratoma and a seminoma in a woodchuck (presumably Marmota monax) have been reported (Sagartz et al. 1972, Anderson \& Johnson 1988, Nyska et al. 1994, Reimer \& Lipscomb 1998).

Mixed testicular tumors involving any combination of Sertoli cell tumor, interstitial (Leydig) cell tumor, and/or seminoma can occur in the testes of an individual animal (Maclachlan \& Kennedy 2002). Nonetheless, terminology may frequently be controversial when assessing multiple tumors. Two subtypes of mixed tumor are currently recognized: (1) mixed germ cell-sex cord stromal tumors that include features of both a seminoma and a Sertoli cell tumor within a single tumor; this type of tumor has properly been designated as a collision tumor, reflecting the interpretation that it represents the interface between 2 distinct tumors, showing no intermixing pattern of growth; and (2) true mixed tumors with both Sertoli and germ cell elements that are intimately admixed in variably sized tubular structures separated by a fibrous stroma of variable density (Maclachlan \& Kennedy 2002).

Collision tumors and true mixed tumors are infrequently reported (Maclachlan \& Kennedy 2002, Michal et al. 2006). A series of such tumors has been described in dogs, and a single case has been described in a stallion (Maclachlan \& Kennedy 2002). Additionally, an interstitial and a Sertoli cell tumor in a domestic ferret (Anderson \& Johnson 1988), mixed Sertoli-Leydig cell tumors in rats (Rehm \& Waalkes 1988), and a testicular teratoma and a seminoma in a woodchuck (Batista-Arteaga et al. 2011) have been reported.

Among described neoplastic conditions in marine mammals, testicular neoplasms are infrequent (Mawdesley-Thomas 1975, Geraci et al. 1987, Newman \& Smith 2006). The potential for metastatic testicular neoplasia in cetaceans has been reported by Estep et al. (2005). In that report, 2 cases of seminomas extended to retroperitoneal lymph nodes. In the 

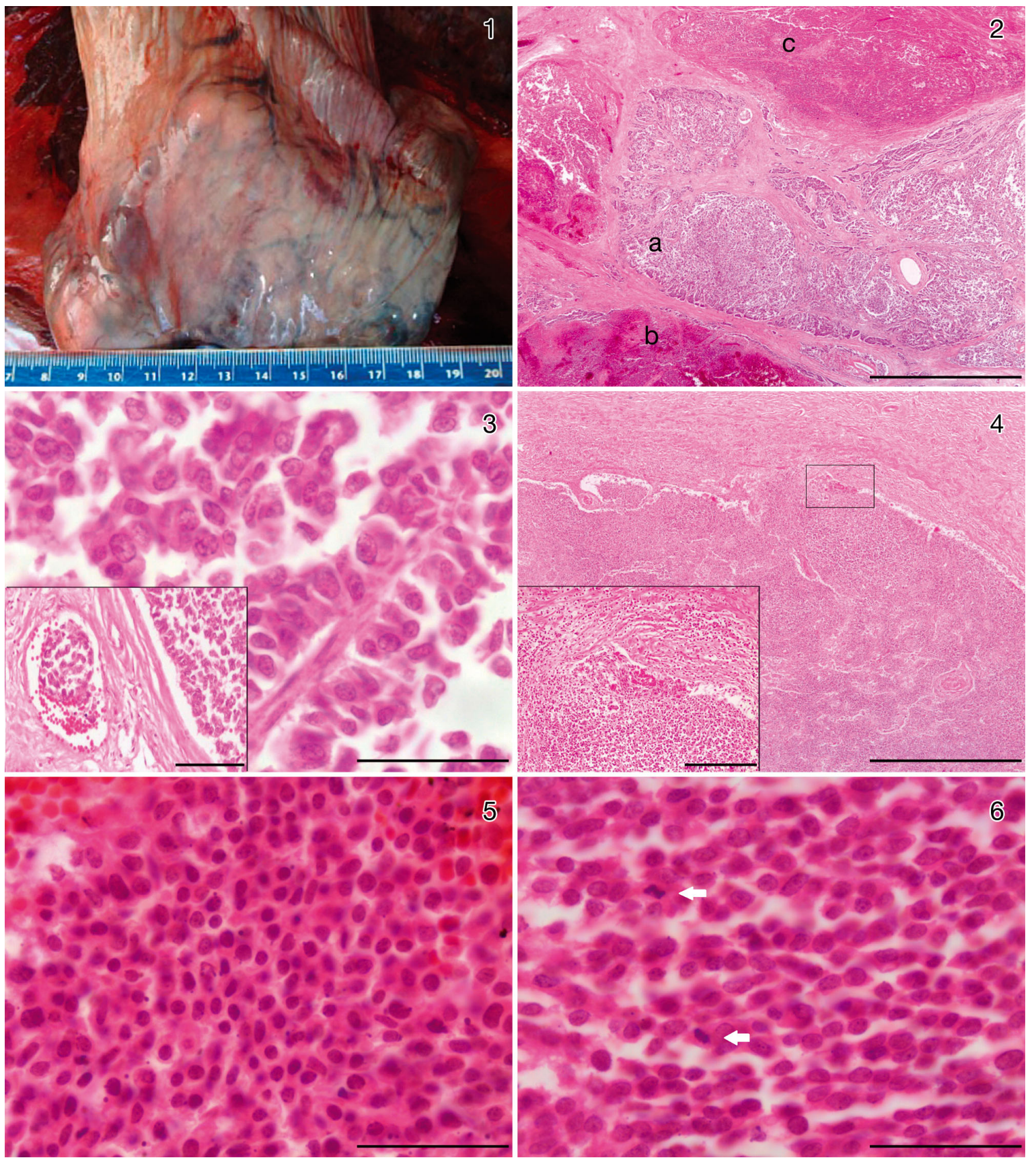

Figs. 1 to 6. Delphinus delphis. Fig. 1. Multifocal nodular lesions bulging from cranial pole of the left testicle, showing no clear demarcation. Note whole testicle irregularity and vascular changes underlying tunica vaginalis. Scale bar is in cm. Fig. 2. Three microscopically distinguishable intraparenchymatous solid nodular lesions in left testicle, multifocally distributed, variably sized, non-capsulated, and showing an expansive growth with atrophy of adjacent seminiferous tubules and prominent fibrosis. (a) Sertoli cell tumor. (b) Interstitial (Leydig) cell tumor. (c) Seminoma. Scale bar $=1000 \mu \mathrm{m}$. Fig. 3. Sertoli cell tumor in testicle with pleomorphic cells consisting of a pallisaded monolayer of cuboidal to spindle-shape cells, supported by a thin connective stroma, with a moderate amount of finely granular eosinophilic cytoplasm, and round to elongate nuclei, finely stippled with heterochromatic chromatin. Scale bar $=20 \mu \mathrm{m}$. Inset: Focal intravascular Sertoli cells embolus adjacent to intraparenchymatous solid growth of neoplastic Sertoli cells. Scale bar $=50 \mu \mathrm{m}$. Fig. 4 . Retroperitoneal lymph node. Scale bar $=$ $500 \mu \mathrm{m}$. Inset: Higher magnification of neoplastic Sertoli cells exhibited in subcapsular sinus. Scale bar $=100 \mu \mathrm{m}$. Fig. 5 . Interstitial (Leydig) cell tumor in testicle. Polyhedral cells, tightly packed, with cell borders poorly demarcated, but intensely eosinophilic cytoplasm, with central, heterochromatic nuclei and finely stippled chromatin. Scale bar $=20 \mu \mathrm{m}$. Fig. 6 . Seminoma in testicle. Round to polyhedral cells, with moderately distinct borders and a pale eosinophilic cytoplasm. Large vesicular nuclei with evident nucleolus. Arrows: Two mitotic figures. Scale bar $=20 \mu \mathrm{m}$ 
present case, neoplastic Sertoli cells successfully reached intratesticular blood vessels and spread into capsular lymphatic vessels and subcapsular sinuses of an adjacent retroperitoneal lymph node. Although no other organ was seen with neoplastic invasion, Sertoli cell tumors should be considered capable of potentially metastasizing in this species.

Sertoli cell tumors are the most hormonally active among testicular neoplasias and are usually associated with a paraneoplastic syndrome comprising feminization derived from released estrogens, which may lead to estrogen-induced pancytopenia. Other signs including bilateral symmetrical alopecia of the trunk and flanks with hyperpigmented inguinal skin, easily detachable dry skin, gynecomasty, pendulous prepuce, male attraction and bone marrow hypoplasia with arregenerative anemia are commonly described clinical signs in human and domestic animal medicine (Maclachlan \& Kennedy 2002, Michal et al. 2006). Despite the above, mixed germ cell-sex cord stromal tumors involving seminoma and Sertoli cell tumors do not induce hyperestrogenic syndromes and are usually benign (Maclachlan \& Kennedy 2002). In our case, absence of clinical signs and necropsy findings did not permit us to demonstrate any of these conditions.

\section{LITERATURE CITED}

Anderson WI, Johnson RC (1988) Testicular teratoma and seminoma in a woodchuck. Vet Pathol 25:400

Batista-Arteaga M, Suárez-Bonnet A, Santana M, Niño T, Reyes R, Alamo D (2011) Testicular neoplasms (interstitial and Sertoli cell tumours) in a domestic ferret (Mustela putorius furo). Reprod Domest Anim 46:177-180

Cowan DF, Walker WA, Brownell RL (1986) Pathology of small cetaceans stranded along southern California

Editorial responsibility: Michael Moore, Woods Hole, Massachusetts, USA beaches. In: Bryden MM, Harrison R (eds) Research on dolphins, Part III. Clarendon Press, Oxford, p 323-367

Estep JS, Baumgartner RE, Townsend F, Pabst DA, Mclellan WA, Friedlaender A, Dunn DG, Lipscomb TP (2005) Malignant seminoma with metastasis, Sertoli cell tumor, and pheochromocytoma in a spotted dolphin (Stenella frontalis) and malignant seminoma with metastasis in a bottlenose dolphin (Tursiops truncatus). Vet Pathol 42: 357-359

Geraci JR, Palmer NC, St. Aubin DJ (1987) Tumors in cetaceans: analysis and new findings. Can J Fish Aquat Sci 44:1289-1300

Irizarry-Rovira AR, Lennox AM, Ramos-Vara JA (2008) Granular cell tumor in the testis of a rabbit: cytologic, histologic, immunohistochemical, and electron microscopic characterization. Vet Pathol 45:73-77

Maclachlan NJ, Kennedy PC (2002) Tumors of the genital systems. In: Meuten DJ (ed) Tumors in domestic animals, 4th edn. Iowa State Press, Ames, IA, p 547-574

Mawdesley-Thomas LE (1975) Some aspects of neoplasia in marine mammals. Adv Mar Biol 12:151-231

Michal M, Vanecek T, Sima R, Mukensnabl P and others (2006) Mixed germ cell sex cord-stromal tumors of the testis and ovary: morphological, immunohistochemical, and molecular genetic study of seven cases. Virchows Arch 448:612-622

> Mitsumori K, Talley FA, Elwell MR (1989) Epididymal interstitial (Leydig) cell tumors in $\mathrm{B}_{6} \mathrm{C}_{3} \mathrm{~F}_{1}$ mice. Vet Pathol 26: 65-69

Newman SJ, Smith SA (2006) Marine mammal neoplasia: a review. Vet Pathol 43:865-880

> Nyska A, Waner T, Goldstein J, Horowitz Y, Harmelin A, Orgad U, Yakobson B (1994) Interstitial cell (Leydig) tumor in an eland (Taurotragus oryx). J Wildl Dis 30:291-294

$>$ Rehm S, Waalkes MP (1988) Mixed Sertoli-Leydig cell tumor and rete testis adenocarcinoma in rats treated with $\mathrm{CdCl}_{2}$. Vet Pathol 25:163-166

$>$ Reimer DC, Lipscomb TP (1998) Malignant seminoma with metastasis and herpesvirus infection in a free-living sea otter (Enhydra lutris). J Zoo Wildl Med 29:35-39

Sagartz JW, Garner FM, Sauer RM (1972) Multiple neoplasia in a captive jungle cat (Felis chaus) - thyroid adenocarcinoma, gastric adenocarcinoma, renal adenoma, and Sertoli cell tumor. J Wildl Dis 8:375-380

Submitted: April 19, 2012; Accepted: August 27, 2012 Proofs received from author(s): November 2, 2012 